\title{
Measurement and Simulation of Energy Use in a School Building
}

\section{Snezana Dragicevic, Aleksandar Peulic, Miroslav Bjekic, Radojka Krneta}

University of Kragujevac, Faculty of Technical Sciences

Svetog Save 65, 32000 Cacak, Serbia

snezana.dragicevic@ftn.kg.ac.rs, aleksandar.peulic@ftn.kg.ac.rs, miroslav.bjekic@ftn.kg.ac.rs, radojka.krneta@ftn.kg.ac.rs

\begin{abstract}
This paper presents the development of a wireless temperature monitoring system and the application of measurement data for computer model validation, and its application to the simulation of energy use in a school building in Cacak, Serbia. The system for temperature monitoring was realized with a GPS/GPRS (Global Positioning System/General Packet Radio Service) system for low power data acquisition, using an MSP430 Texas Instruments microcontroller. With respect to heat loss analysis, the continual measurement of ambient and inside temperatures with a sampling time of one hour has been performed. For the simulation, DesignBuilder software is used. The simulation model, which reproduces the temperature measurement of school buildings, was developed and tested for energy analysis. Results are used to develop generalized guidelines for the determination of the efficiency of energy saving measures and the evaluation of low-energy buildings.
\end{abstract}

Keywords: temperature measurement; energy efficiency; low power microcontroller; DesignBuilder simulation

\section{Introduction}

High-energy consumption is one of the most serious problems in the world today. Recently, this topic has encompassed not only economic but also ecological and social importance. School buildings are typical structures, and their optimal energy consumption is a matter of public interest. Defining measures to improve the energy efficiency of school buildings is very important. There are several reasons for the implementation of priority measures for the energy optimization of school facilities: the number of these buildings, the need to maintain ambient comfort during the day and during most of the year, and the large amount of thermal and electrical energy used to maintain that comfort. Schools usually have a high level of energy consumption due to their considerable heating requirements 
and high electricity usage for lighting and equipment. The typical annual heating consumption of some European school buildings is reported as $96 \mathrm{kWh} / \mathrm{m}^{2}$ in Ireland, $192 \mathrm{kWh} / \mathrm{m}^{2}$ in Slovenia, and $157 \mathrm{kWh} / \mathrm{m}^{2}$ in the UK [1]. Specific energy consumption in buildings in Serbia is 3-4 times larger, and there is great potential for an increase in energy efficiency.

The heating energy demand of a school building is influenced by construction, building services, weather, surroundings and the way it is used. The impact of the individual influencing factors is not considered. Stationary computer models of buildings are usually too coarse to identify details of all the temperature distributions or energy flows that are relevant for the consideration of energy demand and comfort [2,3]. Furthermore, dynamic simulations can be very complex. However, in practice most of the numerous parameters cannot be determined precisely, because they are not fixed by the construction plans and/or are difficult to measure in a building $[4,5]$.

This paper presents the development of a wireless temperature monitoring system, and the application of the measurement data for computer model validation, which is used for the dynamic simulation of energy use in schools. Validated computer models for energy building simulation have an advantage in that the accuracy of the temperature prediction of the model over a short time scale is known. This allows the making of reliable predictions on time-dependent effects.

\section{The School and Wireless Measurement Procedure}

The selected school is a primary school, "Vuk Karadzic", in Cacak, Serbia. The building has a total area of $4,236 \mathrm{~m}^{2}$, an external facade surface of $2,700 \mathrm{~m}^{2}$ and a facade window area of $487 \mathrm{~m}^{2}$. Measurements of internal and external temperatures are well suited for precise predictions of heating energy demand and comfort of buildings and suggestions of modifications to them [6]. Continual measurements of ambient and outside temperatures, with a sampling time of one hour, were performed during the winter months. The measurements of ambient temperature were performed in two classrooms: one with old windows with wooden frames (overall coefficient of heat transfer of $3.49 \mathrm{~W} / \mathrm{m}^{2} \mathrm{~K}$ ), whereas in the other there are new PVC windows (overall coefficient of heat transfer of $1.49 \mathrm{~W} / \mathrm{m}^{2} \mathrm{~K}$ ). These two classrooms have equal dimensions of $59.40 \mathrm{~m}^{2}$ and very similar positions, so it can be assumed that other relevant thermal parameters are also almost the same. The surface area of the windows in both classrooms is 18.48 $\mathrm{m}^{2}$.

The temperature measurement system is performed by a Global Positioning System/General Packet Radio Service (GPS/GPRS) based wireless acquisition system. The basis of the hardware part of the GPRS-based system for data acquisition (GPRSuC) from remote locations consists of a low power 
MSP430F147 microcontroller and Telit GM-862 GPRS/GSM/GPS module (Fig. 1) $[7,8]$. In addition to the standard functions of the devices used in M2M (Machine to Machine) communication, this module has a GPS receiver as well as a dedicated GPS port on which the data obtained from the GPS are shown in NMEA (National Marine Electronics Association) format. This makes the entire platform applicable not only for monitoring of the temperature, but also for the acquisition of data from measuring sites whose locations are not fixed. In addition to GPRS, GPS Telit is also able to send text messages through SMS (Short Message Service).

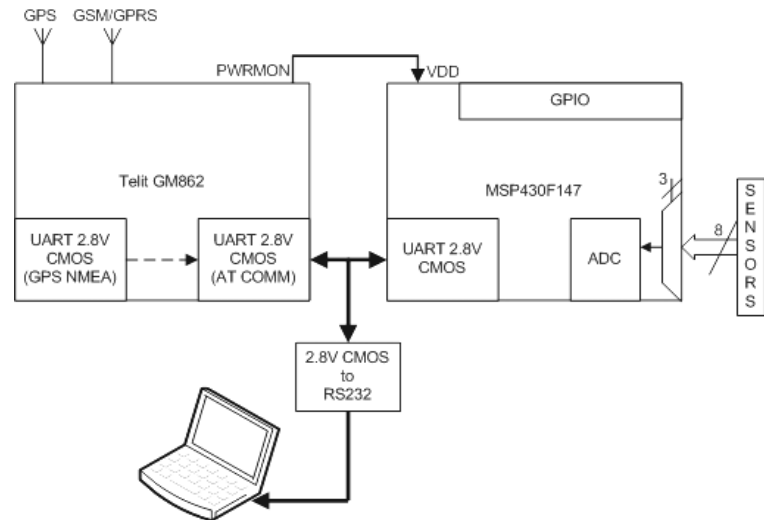

Figure 1

The structure of GPRS microcontroller system

Communication takes place via the AT port between the microcontroller on one side and the Telit module on the other using AT commands. GPS sentences are encapsulated in AT commands. AT commands are also used to send text messages through SMS. The system's operating range is $-10{ }^{\circ} \mathrm{C}$ to $+55^{\circ} \mathrm{C}$, which can be a potential problem if GPRSuC is used in environments with very low temperatures.

A power supply voltage is appropriate for battery powered systems and it is set at 4.2 V. The GSM modem is made in a way that the RF transmission is not continuous; rather, it is packed into bursts at a base frequency of about $216 \mathrm{~Hz}$. Consequently, relative current peaks can be as high as $2 \mathrm{~A}$, and therefore the power supply is designed with a linear voltage regulator LM317K with a maximum continuous current of $2 \mathrm{~A}$.

Microcontroller selection is conditioned by the requirements for small consumption and low voltage power supply. A maximum consumption of $560 \mathrm{uA}$ at $3.0 \mathrm{~V}$ supply voltage and a frequency of the external oscillator of $32768 \mathrm{KHz}$ make this microcontroller one of the best on the market from the point of view of power consumption. Low consumption is important because the microcontroller is powered over the PWRMON pin of the Telit module, which is normally used for an indication of operation. The PWRMON pin establishes a high voltage level, which provides sufficient power for the microcontroller MSP430F147, $900 \mathrm{~ms}$ 
after powering up the Telit module. Digital inputs and outputs are $2.8 \mathrm{~V}$ CMOS type, so it is not necessary to implement a circuit for level shifting between the microcontroller and UART peripherals of the Telit module. The microcontroller has a 12-bit, 8 channel mixed A/D converter with successive approximations.

The firmware is written in $\mathrm{C}$, and its structure is shown in Figure 2. The Telit module acts as a slave carrying out the commands sent by the microcontroller.

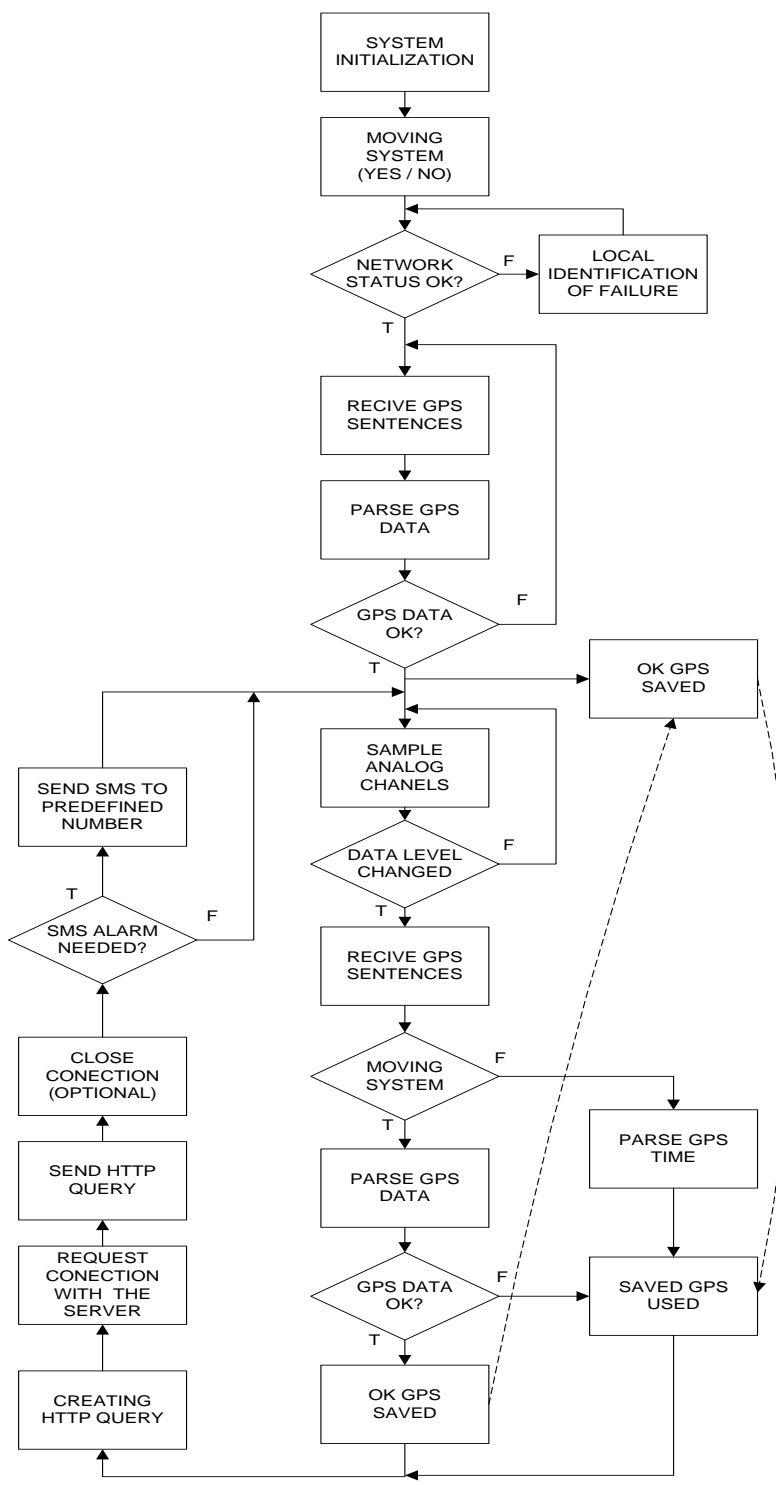

Figure 2

Flowchart of the firmware 
Since the platform is designed to be suitable for the monitoring of mobile locations, GPS accuracy is very important. Since the system has an independent power supply and consumption is highest in GPRS communication, it is very important to decrease the level of communication without losing the significance of the data. A real system prototype is shown in Figure 3.

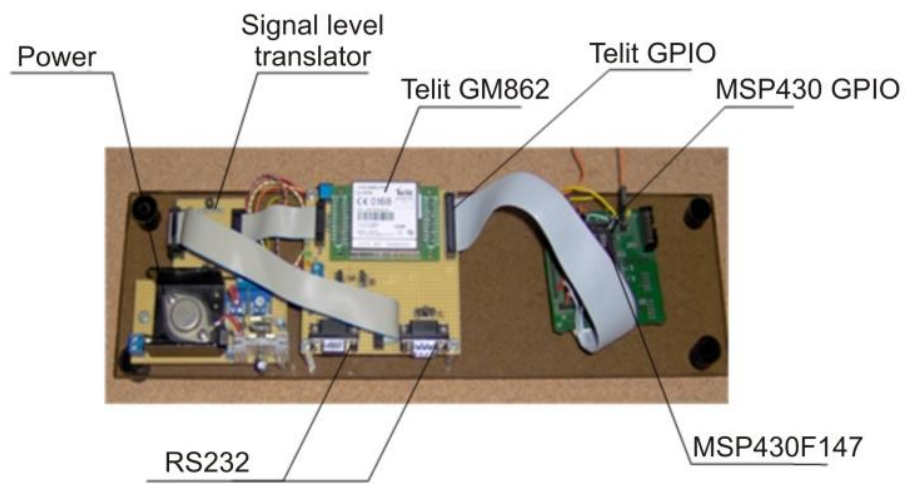

Figure 3

A prototype of temperature monitoring system

General Packet Radio Services' standard allows data transfer in a completely different way from the Circuit Switch Data (CSD) type of transmission. In CSD, data are transmitted by directly establishing a connection with other, remote modems, so all devices in-between are used to provide a simulation of the physical connection between the final points (point-to-point connection). Besides the obvious disadvantage in terms of low utilization of network resources, there are also problems of long delays in establishing a connection and high fees for the use of network resources, based on the time period of the established link, not the amount of data as with GPRS. One message from the remote acquisition system consists of eight measured parameters, a time stamp and identification field, and has nearly 110 bytes, so it is appropriate to use the GPRS system [9]. It is important to note that the system has no fixed IP address. Mobile operators provide a fixed IP address service, and it is possible to achieve communication in both directions with changes in the overall software of the system.

A practical part of this study is to present the collected data. It is only possible to pass parameters and values in some other way if a specified URL http request is made. The entire software solution has been realized using open source J2EE technology. The part of the software used to exchange data with the hardware is the interface, with no visual interpretation, and it is only executed when the HTTP request is passed to the Servlet by a device that forwards data. It has been developed as a Java Servlet, the hardware of which calls using the HTTP GET request to obtain the appropriate data Servlet, which performs the same processing and saves the results in the MySQL database. The Servlet can be accessed with the use of HTTP requests from anywhere in the world. 
As the container, the Apache Tomcat version 6.0.16 is used. The project is implemented as a Web application, which is located on the server in the Computer Science Laboratory of the Technical faculty in Cacak, Serbia, and which provides current monitoring of temperatures and displays their values in real time. Since a system sends GPS coordinates, GIS support is used for better data presentation. As geographical support for the project, the Google Maps API is used. The principle of working with Google Maps API is that a complete GIS system is on Google's server. The user passes the coordinates and parameters for the display to the corresponding server, which replies by sending the required graphical content. Google Maps usage is free of charge and offers different types of presentation. Mouse clicking on the marker surface displays the current parameter values for the checking system (Fig. 4). The web application is built to monitor more than one data acquisition system. There is also a possibility of historical observation of measured parameters.
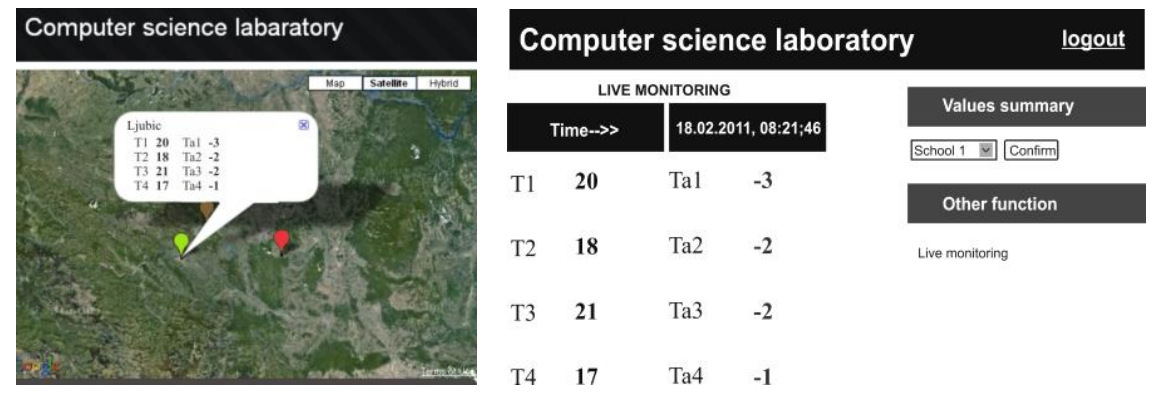

Figure 4

Multiple systems monitoring with data presentation on Google map and laboratory portal

\section{Simulation Model and Validation}

Building energy simulation is the analysis of the energy performance of buildings using computer modelling and simulation techniques. The calculation of building loads and energy consumption are used to determine the energy characteristics of the building and its building systems. Building energy simulation is employed to design the building to the requirements of local building regulations, codes and standards. Subsequently, it can supplement energy auditing to check the energy performance of the as-built building. With building energy simulation, complicated design problems can be investigated and their performance can be quantified and evaluated. It is also a useful tool for developing a better understanding of the building's performance [10]. 
For the simulation of the thermal behavior of the selected school building, the simulation software DesignBuilder ${ }^{1}$ has been used (Fig. 5). This software is based on the Energyplus code and is provided with a 3D interface and meteorological database. It is based on the most popular features and capabilities of BLAST and DOE-2, as a stand-alone simulation.

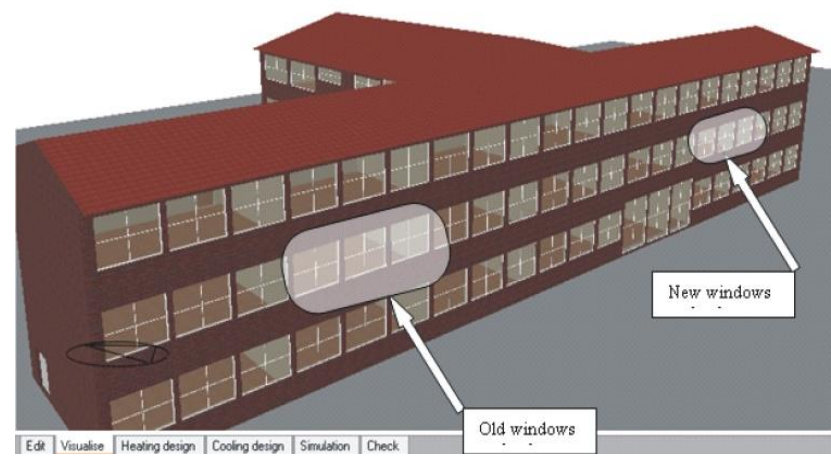

Figure 5

DesignBuilder model of school building

For all simulations, information on the wall, roof and flooring construction, as well as the windows and building services, are taken from the construction plans. The reproduction of the user behavior was necessary to yield the best possible validation of the simulation models. The basic parameters used for energy simulations are given in Table 1.

Table 1

Description of Classrooms

\begin{tabular}{|c|c|c|c|c|}
\hline \multicolumn{5}{|l|}{ Overall } \\
\hline Construction & Layers & Material & $\begin{array}{c}\text { Thickness } \\
(\mathrm{m})\end{array}$ & $\begin{array}{c}\text { U value } \\
\left(\mathrm{W} / \mathrm{m}^{2} \mathrm{~K}\right)\end{array}$ \\
\hline External walls & $\begin{array}{l}\text { Outermost layer } \\
\text { Layer } 2 \\
\text { Layer } 3 \\
\text { Innermost layer }\end{array}$ & $\begin{array}{l}\text { brickwork } \\
\text { air gap } \\
\text { brickwork } \\
\text { plaster }\end{array}$ & $\begin{array}{l}0.105 \\
0.050 \\
0.105 \\
0.013 \\
\end{array}$ & 1.562 \\
\hline $\begin{array}{l}\text { Internal } \\
\text { partitions }\end{array}$ & $\begin{array}{l}\text { Outermost layer } \\
\text { Layer } 2 \\
\text { Innermost layer }\end{array}$ & $\begin{array}{l}\text { gypsum plastering } \\
\text { concrete block } \\
\text { gypsum plastering }\end{array}$ & $\begin{array}{l}0.013 \\
0.100 \\
0.103 \\
\end{array}$ & 1.212 \\
\hline Ceilings & Single layer & ceiling tiles & 0.020 & 1.692 \\
\hline Glazing & \multicolumn{3}{|c|}{$44 \%$ of gross floor area } & 3.187 \\
\hline
\end{tabular}

\footnotetext{
${ }^{1}$ http://www.designbuilder.co.uk
} 


\begin{tabular}{|c|c|c|}
\hline \multicolumn{3}{|c|}{ HVAC System } \\
\hline \multicolumn{2}{|c|}{ Thermostat Settings } & $20^{\circ} \mathrm{C}$ heating \\
\hline \multicolumn{2}{|c|}{ Schedule } & 8:00 am - -6:00 pm, "off" night and weekends \\
\hline \multicolumn{3}{|c|}{ Internal gains } \\
\hline Occupancy & \multicolumn{2}{|c|}{$3 \mathrm{~m}^{2} /$ person } \\
\hline Lighting & \multicolumn{2}{|c|}{$3.4 \mathrm{~W} / \mathrm{m}^{2}, 100 \mathrm{lux}$} \\
\hline Receptacles & \multicolumn{2}{|c|}{$<100 \mathrm{~W}$ (periodic usage of overhead projector, computer) } \\
\hline Schedule & \multicolumn{2}{|c|}{$\begin{array}{l}\text { 8:25 am- } 3: 30 \text { pm weekdays, with some teacher occupancy before and } \\
\text { after regular class hours }\end{array}$} \\
\hline
\end{tabular}

Figure 6 shows the inside temperatures measured in the selected classroom, as well as the ambient temperatures. In the same figure, the results of the hourly temperature analysis in DesignBuilder are presented in order to compare the results of the simulations with measured data. Interior and exterior temperatures were predicted using DesignBuilder 1.8 software. All material and construction details, as discussed previously, have been applied to the simulation program, and a real weather data file for Cacak has been used in the simulation.

The good agreement of the simulations with the measurements from the temperatures analyzed indicates the successful modelling of the school building envelope presented and its heat losses. A reproduction of user behavior was necessary to yield the best possible validation of the simulation models.

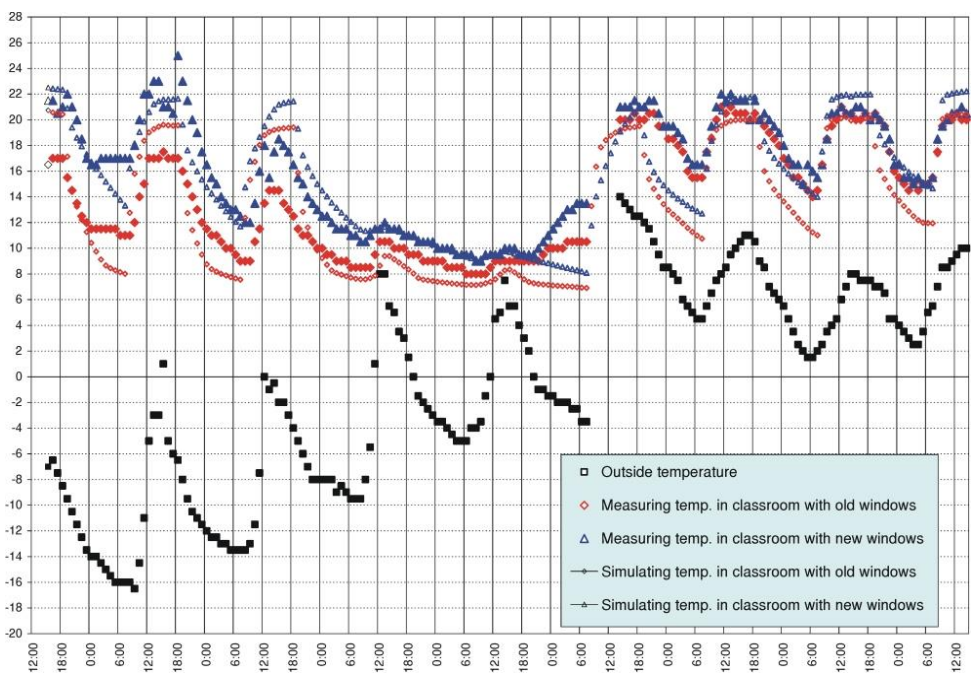

Figure 6

Simulated and measured indoor and outdoor air temperatures

In addition, dynamic simulations of heat losses from the school building are performed. The results from the DesignBuilder dynamic simulation include hourly heat losses and gains through windows, walls, ceilings, solid floors and partitions 
for classrooms with old windows and for classrooms with new windows (Fig. 7). Heat losses through windows with external infiltration are specially calculated.

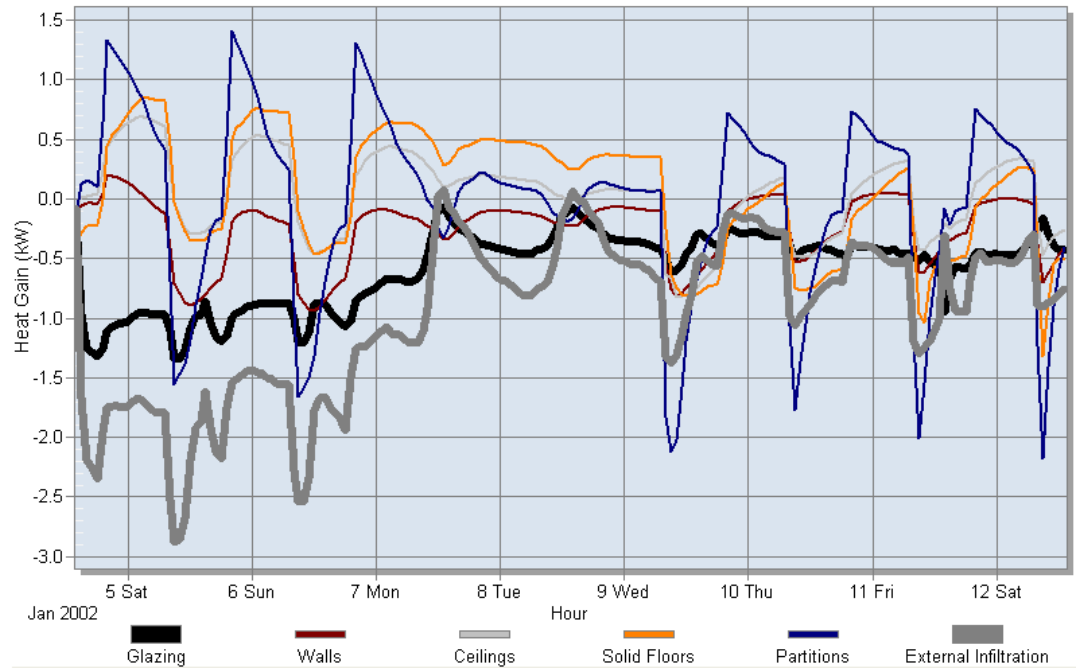

a)

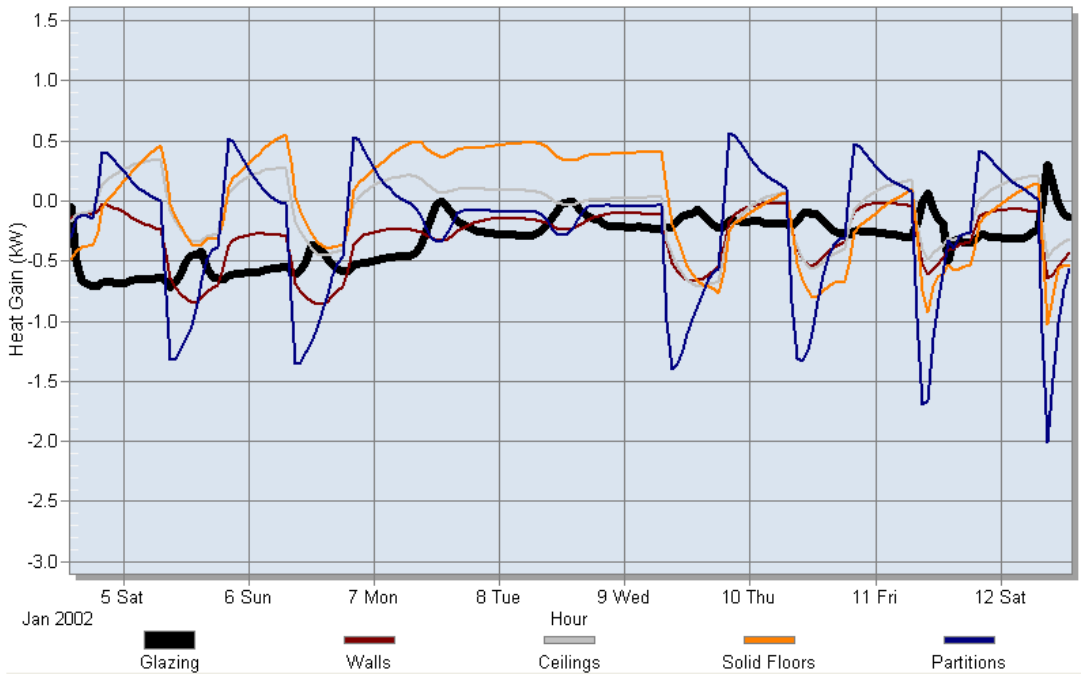

b)

Figure 7

DesignBuilder simulation results for classroom heat gains: a. Old window; b. New window

The replacement of old windows can effectively decrease heat losses by up to $50 \%$ for an ambient temperature from $-5{ }^{\circ} \mathrm{C}$ to $-15{ }^{\circ} \mathrm{C}$, while for higher ambient temperatures the heat losses could decrease by up to $18 \%$. 
Transmitted solar gains and HVAC heating for the classrooms with both old and new windows are shown in Figure 8. Heat gains through windows are negligible because the simulation period did not include any sunny days.

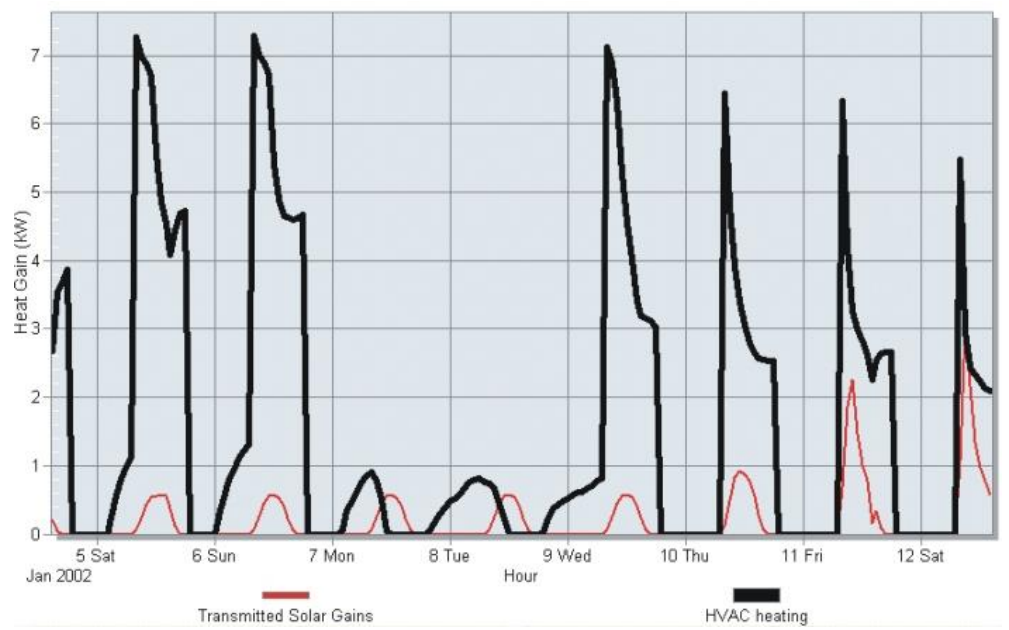

a)

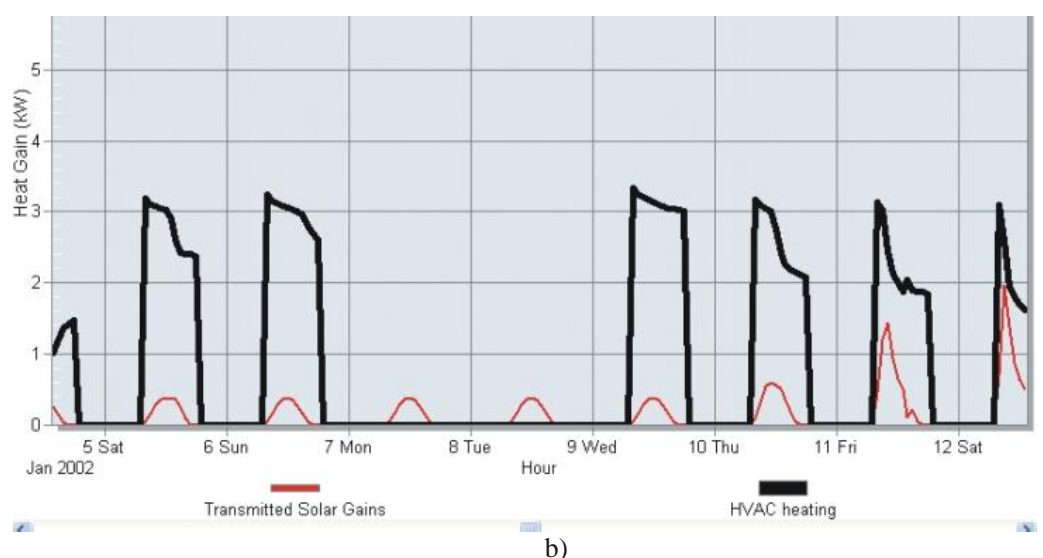

Figure 8

DesignBuilder simulation results for classroom HVAC heating and solar gains:

a) Old window; b) New window

The simulation results confirm the adequacy of window replacement from a viewpoint of heating energy savings. At an ambient temperature of $0{ }^{\circ} \mathrm{C}, \mathrm{HVAC}$ heating for the classroom with old windows is twice as great as the classroom with new windows; at $-18{ }^{\circ} \mathrm{C}$, the HVAC heating for the classroom with old windows is 2.41 times greater. 
The results of the DesignBuilder dynamic energy simulation of the school building, for the cases with the old and new windows, monthly and annual energy consumption for space heating could be estimated. Table 2 shows average monthly heat energy consumption in the winter months for the school building with old and new windows.

Table 2

School heat energy consumption in the winter months (MWh)

\begin{tabular}{|l|c|c|}
\hline \multicolumn{1}{|c|}{ Month } & Old windows & New windows \\
\hline October & 0.315 & 0.040 \\
\hline November & 6.784 & 2.897 \\
\hline December & 23.917 & 16.368 \\
\hline January & 26.502 & 17.799 \\
\hline February & 16.690 & 10.087 \\
\hline March & 2.102 & 0.289 \\
\hline
\end{tabular}

Implementation of the proposed energy efficiency improvements in the school building would provide annual energy savings of $29 \mathrm{MWh}$, i.e. 37\%, and reduction of the carbon-dioxide emissions of $10.5 \mathrm{tCO} 2$ into the atmosphere per year.

\section{Conclusions}

In this paper, a flexible measurement system for the temperature monitoring of a school building is proposed. The system communication is completely wireless, easily operable and has a low power requirement. Another consideration of this study was the suitability of the DesignBuilder software for simulating the thermal performance of the selected school. The developed and validated model is used for building energy simulation in order to analyze the effects of the replacement of windows. The building model is validated according to the energy demand and indoor temperature, and can, therefore, be used to analyze the impacts of various parameters on the heating energy demand and comfort. The results show satisfactory agreement with the measured temperature profiles for the analyzed classrooms. With this building model, the impact of the main influencing factors on the real heating energy demand can be analyzed quite precisely.

\section{Acknowledgements}

This paper was supported by the Ministry of Education and Science of the Republic of Serbia within the project "Improvement of energy characteristics and quality of interior space in the buildings of educational institutions in Serbia and the impact on health" under $\mathrm{N}^{\mathrm{o}} .42008$ (2011-2014).

\section{References}

[1] Airaksinen, M.: Energy Use in Day Care Centers and Schools, Energies, 4, 2011, pp. 998-1009 
[2] Desideri, U., Proietti, S.: Analysis of Energy Consumption in the High Schools of a Province in Central Italy, Energy and Buildings, 34, 2002, pp. 1003-1016

[3] Yiqun, P., Mingming, Z., Gang, W.: Whole Building Energy Simulation and Energy Saving Potential Analysis of a Large Public Building, Journal of Building Performance Simulation, 4, 2011, pp. 37-47

[4] Gieseler, U. D. J., Heidt, F. D., Bier., W.: Combined Thermal Measurement and Simulation for the Detailed Analysis of Four Occupied Low-Energy Buildings, $8^{\text {th }}$ International IBPSA Conference, Eindhoven, The Netherlands, 2003, pp. 391-398

[5] Oka, S., Sedmak, A., Djurovic-Petrovic, M.: Energy Efficiency in Serbia Research and Development Activity, Thermal Science, 10, No. 2, 2010, pp. $5-32$

[6] Krneta, R., Dragićević, S., Radovanović, M., Bjekić, M., Energy Consumption in Schools in Serbia - Review of Present State in Cacak Municipality, Journal on heating, refrigerating and air-conditioning, Vol. 34, No. 1, 2005, pp. 49-53

[7] Alkar, A. Z.: An Internet-based Wireless Home Automation System for Multifunctional Devices, IEEE Trans. Consumer Electron., 51, No. 4, 2005, pp. $1169-1174$

[8] Gutierrez, J. A., Naeve, M., Callaway, E., Bourgeois, M., Mitter, V., Heile, B.: IEEE 802.15.4: a Developing Standard for Low-Power Low-Cost Wireless Personal Area Networks, IEEE Network, 15, No. 5, Sept-Oct. 2001, pp. 12-19

[9] Alheraish, A.: Design and Implementation of Home Automation System, IEEE Trans. Consumer Electron., 50, No. 4, 2004, pp. 1087-1092

[10] Shetal, W., Sharples, S.: A Building Simulation Sustainability Analysis to Asess Dwellings in a New Cairo Development, Fourth National Conference of IBPSA-USA, New York City, New York, August 11-13, 2010, pp. 94101 